\title{
Evaluation of Retention of Custom- Made Posts Using Different Types of Luting Cements - An In-Vitro Study
}

\author{
Dr. Muthuraj. $\mathrm{Hl}^{1}$, Dr. Mahesh $\mathrm{M} \mathrm{S}^{2}$, Dr. Naresh Lingaraju ${ }^{3}$, \\ Dr. Smitha. $\mathrm{M}^{4}$ \\ 1Department of Maxillofacial Prosthodontics Farooqia Dental College and Hospital Mysore. \\ 2Department of Oral Medicine and Radiolog yFarooqia Dental College and Hospital Mysore \\ 3Professor and Head Department of Oral Medicine and Radiology Farooqia Dental College \\ and Hospital Mysore \\ 4Department of Maxillofacial Prosthodontics NSVK SV Dental College and Hospital Bangalore
}

\begin{abstract}
This study was selected to evaluate and compare: The tensile strength of custom made posts using three different luting cements, namely Zinc phosphate cement (HARVARD), Glass ionomer cement (FUJI 1$G C$ ), Rely X U-100 Dual cure adhesive resin cement (3M ESPE). Sixty extracted single rooted mandibular premolar teeth were selected. Biomechanical preparation done, obturated and then post space prepared using peeso-reamer. The custom made nickel-chromium posts were fabricated for individual teeth. Posts were luted with three different adhesive luting cements and mounted on an acrylic block. The plastic cylindrical tubes were used to embed the specimens in auto polymerizing acrylic resin block. The whole assembly was gripped in a three jawed chuck and connected to the testing machine. The specimens were tested for tensile bond strength using an Instron testing machine. The machine was run to a cross head speed of $1 \mathrm{~mm} / \mathrm{min}$. increasingly, heavy tensile load were applied to the specimen, till the post comes out the root canal by breaking the cement medium. The results were recorded in Newton's and then converted to kilograms by dividing by 9.81. Retentive qualities were then statistically analyzed.
\end{abstract}

Keywords: Zinc Phosphate cement, Rely X U-100, Glass Ionomer Cement, Specimen)

\section{Introduction} dentistry. ${ }^{1}$

The successful restoration of an endodontically treated tooth is an ongoing challenge for a restorative

Recent advances in the endodontic therapy have provided dentist, the ability to retain teeth that would have been extracted without hesitation just a few decades ago. Studies have shown that more endodontically treated teeth are lost due to poor post endodontic restoration. Sound endodontic treatment followed by proper post and core restoration return the tooth to form, function, esthetic and the pulpless tooth can serve significantly greater longevity than do non-restored tooth.

The post endodontic restoration very often includes fabrication of post and core and has been used to provide long term tooth structure replacement for endodontically treated teeth with moderate to severe damage. Posts are best used for single-rooted teeth and may be fabricated directly or indirectly. ${ }^{1}$

Studies have reported that design, length character of the surface of the endodontic post have an influence on their retentive properties. Further more a luting agent to retain a post can affect the prognosis of a restoration. All posts gain their definitive retention by cementation into a prepared root. ${ }^{1}$

The luting agents currently available for dental restoration are zinc-phosphate, polycarboxylate, glass ionomer, resin-modified glass ionomer, compomer and adhesive resin cements. Advance in the cement system has provided today's dentist to have choice of various luting cements which has unique properties and better retentive factors. But zinc phosphate cement has historically been used as a cementing agent and remains as a common standard for comparison. ${ }^{3}$

\section{Aims \& Objectives}

The aim of this study is to evaluate the tensile strength of the three various luting cements using custom made posts cemented in a prepared natural teeth.

The objective of this study is to compare the tensile retentive force of zinc phosphate cement; glass ionomer cement and dual cure adhesive resin cement on retention of posts. 


\section{Materials And Methods}

This study was conducted to evaluate the tensile retentive strength of the three different luting cements using custom made posts. The study was done at the Department of Prosthodontics, The Oxford Dental College and Hospital, Bangalore.

The armamentarium and materials used in this study are:

\begin{tabular}{|c|c|c|c|}
\hline $\begin{array}{l}\text { SI } \\
\text { No. }\end{array}$ & Materials & Type & Manufacturer \\
\hline 1. & Samples & $\begin{array}{l}60 \text { extracted, single rooted human } \\
\text { mandibular premolars }\end{array}$ & - \\
\hline \multirow[t]{3}{*}{2.} & \multirow[t]{3}{*}{ Hand piece } & Aerotor hand piece & $\begin{array}{l}\text { NSK Pana Air E- } \\
\mathrm{T}\end{array}$ \\
\hline & & $\begin{array}{l}\text { E-type contra-angle micromotor hand } \\
\text { piece }\end{array}$ & $\begin{array}{l}\text { NAC - E (NSK, } \\
\text { Nakanishi INC, } \\
\text { Japan) }\end{array}$ \\
\hline & & E-type straight micromotor hand piece & $\begin{array}{lr}\text { Ex-6 } & \text { NSK, } \\
\text { Nakanishi } & \text { Inc, } \\
\text { Japan) } & \\
\end{array}$ \\
\hline 3. & Abrasives & Carborundum discs (15/16") & $\begin{array}{l}\text { Dentorium, New } \\
\text { York, N.Y }\end{array}$ \\
\hline \multirow[t]{26}{*}{4.} & \multirow[t]{20}{*}{ Armamentarium } & Straight probe & -1 \\
\hline & & Tweezer & - \\
\hline & & Metallic scale & - \\
\hline & & Cement spatula & - \\
\hline & & Agate spatula & - \\
\hline & & Glass slab & - \\
\hline & & Paper mixing pad & \\
\hline & & Dappen dish & \\
\hline & & Gates glidden drills (Size1-6) & Mani Inc, Japan \\
\hline & & Peeso reamers (sizes 1-4) & Mani Inc, Japan \\
\hline & & Stainless steel hand pluggers (Sizes 15-40) & Mani Inc, Japan \\
\hline & & $\begin{array}{l}\text { Stainless steel hand spreaders (Sizes 15- } \\
40 \text { ) }\end{array}$ & Mani Inc, Japan \\
\hline & & Barbed broaches (Sizes 15-40) & Mani Inc, Japan \\
\hline & & Paper points (Sizes 15-40) & Mani Inc, Japan \\
\hline & & Tooth picks -60 & - \\
\hline & & Inlay casting wax & $\begin{array}{l}\text { GC Company, } \\
\text { Tokyo, Japan }\end{array}$ \\
\hline & & Nickel Chromium Alloy & Bego \\
\hline & & $\begin{array}{l}\text { Phosphate bonded investment material - } \\
\text { Bellasun }\end{array}$ & Bego \\
\hline & & Applicator brushes & 3M ESPE \\
\hline & & Light curing unit -2500 & 3M ESPE, USA \\
\hline & a. Irrigant & $3 \%$ sodium hypochlorite $(\mathrm{NaO} \mathrm{Cl})$ & $\begin{array}{lr}\text { Vensons } & \text { India } \\
\text { Pvt } & \text { Ltd, } \\
\text { Bangalore } & \end{array}$ \\
\hline & $\begin{array}{ll}\text { b. } & \text { Resin based } \\
\text { sealer }\end{array}$ & Epoxy resin (AH-Plus) & $\begin{array}{l}\text { Dentsply, } \\
\text { Maillefer, Paris }\end{array}$ \\
\hline & $\begin{array}{ll}\text { c. } & \text { Obturation } \\
\text { material }\end{array}$ & Gutta-percha points (Sizes 10-40) & $\begin{array}{l}\text { Dentsply, } \\
\text { Maillefer, Paris }\end{array}$ \\
\hline & \multirow[t]{3}{*}{ Luting cement } & Type I Glass Ionomer Cement (Fuji I) & $\begin{array}{l}\text { GC Company, } \\
\text { Tokyo, Japan }\end{array}$ \\
\hline & & Zinc phosphate cement & Harvard \\
\hline & & Dual cure resin cement & $\begin{array}{l}\text { U-100, 3M India } \\
\text { Ltd }\end{array}$ \\
\hline \multirow[t]{4}{*}{7.} & \multirow[t]{4}{*}{ Others } & $\begin{array}{l}\text { Plastic tube }(2 \mathrm{~cm} \text { diameter, } \\
\text { height })\end{array}$ & \\
\hline & & Cold cure acrylic & $\begin{array}{l}\text { DPI-RR cold } \\
\text { cure } 156887 \\
\text { Type II Class I }\end{array}$ \\
\hline & & Surveyor & $\begin{array}{l}\text { Shin Precision } \\
\text { industrial Co. }\end{array}$ \\
\hline & & Instron testing machine & $\begin{array}{ll}\text { Model } & 5586, \\
\text { Instron } & \text { Corp, } \\
\text { Canton, } & \\
\text { Massachusetts, } \\
\text { SMS, SS-35N, } \\
\text { SAE }\end{array}$ \\
\hline
\end{tabular}


Collection Of Samples: Sixty human single rooted mandibular premolars free from caries, restoration or cracks were selected for this study ${ }^{1}$ [FIG 1]. All the selected teeth had comparable root length and adequate bulk of dentin to allow standard post placement. These teeth after their extraction had been stored in normal saline at room temperature ${ }^{3,9}$.

Types Of Posts Materials: In this study the alloy used for the fabrication of custom posts was Beryllium free Nickel Chromium alloy (Bego)

\section{Method}

Preparation Of Samples: The teeth were decoronated approximately $1 \mathrm{~mm}$ coronal to the cemento-enamel junction ${ }^{1,9}$ using carborundum disks rotating at slow speed, in a micro motor straight hand piece, at right angle to the long axis, leaving a flat surface of the root [FIG 14]. Any root with detectable fracture lines on transillumination was discarded ${ }^{15}$.

The Biomechanical Preparation: The canals were negotiated with sizes 10 and 15 stainless steel K-files, until the tip of size 15 was observed to exit from the apical foramen. Working length was then established $0.5 \mathrm{~mm}$ short of this length. The canals were then subsequently enlarged using successively larger stainless steel K-files till size 40 [FIG 15] and irrigated with sodium hypochlorite ${ }^{3,11}$. The size of master apical file was kept constant at 25 . The canals were also recapitulated with a size $25 \mathrm{~K}$-file to ensure patency of the canal terminus. After the biomechanical preparation was complete, canals were thoroughly dried using paper points ${ }^{2}$. Obturation was done using a lateral condensation method [FIG 16], wherein a primary cone and several accessory Gutta Percha cones were placed within the root canal along with epoxy resin sealer AH-26 [FIG 3] and a spreader was used to condense the cones together.

The obturated teeth were stored in normal saline for 24 hours $^{2}$. After 24 hours, ensuring the complete set of the RC sealer, the post canal space for each of the 60 obturated premolars was prepared using Peeso reamers no 1-3. The post canal space was enlarged to the final size using the no 4 Peeso reamers [FIG 17]. The length of the post canal space was standardized at $9 \mathrm{~mm}^{3}$. A rubber stop was placed exactly for $9 \mathrm{~mm}$ length of peeso reamer during the post space preparation.

Distribution Of Samples: The teeth were divided into 3 groups, each containing 20 teeth. Different luting cements were used in each group to lute the post into the root canal.

Group A $\quad$ - Dual cure adhesive resin cement. [FIG 4]

Group B $\quad$ - $\quad$ Glass ionomer cement [FIG 5]

Group C $\quad$ - $\quad$ Zinc phosphate cement. [FIG 6]

Preparation Of Cast Post: Patterns for the cast posts were fabricated in inlay wax (GC Company, Tokyo, Japan) [FIG 7]. The wax was placed inside the canal using well trimmed wooden tooth picks as carrier [FIG 18]. Accurate registration of the canal walls was ensured during fabrication of the wax patterns. A plastic loop was placed at the end of the pattern [FIG 19] to allow attachment for the universal testing machine during tensile testing ${ }^{1,3,11}$.

Powder: Liquid Ratio: Investing was done following the manufacturer's recommendations-Bellasun (Bego) investment material [FIG 9]. Investing was accomplished at a constant room temperature of $28-30{ }^{\circ} \mathrm{C}$ and the investment liquid and powder were also maintained at the room temperature. Investment material powder was mixed with a mixture of its special liquid and double distilled water at the recommended ratios $\{160 \mathrm{gm}$ of investment material to $24 \mathrm{ml}$ of liquid [30\% investment liquid (Begosol) $+70 \%$ Double distilled water].

Mixing \& Investing: First, liquid was put into a clean rubber bowl and then the powder was added. Mixing was done thoroughly with a spatula for approximately 10-15 seconds, after hand spatulation was over; mixing was done for 60 seconds in a vacuum mixer (Easy Mix- Bego). Mixed investment was poured in the ring with mild vibration on an investment vibrator. Excessive vibration was avoided as it would lead to settling of the solids in the investment and allows free water accumulation adjacent to the wax pattern, resulting in surface roughness.

Bench Set: The mold was kept for 30 minutes for bench set [FIG 19]. Carbon free investment was selected because carbon is known to embrittle the alloy containing nickel and chromium. The latest evidence indicates that nickel can react with carbon at temperature above $1504^{\circ} \mathrm{C}$. For the same reason carbon crucibles were not used in this study instead ceramic containing quartz crucibles were used. 


\section{Preheating And Heating Procedure}

The invested molds were placed in preheated furnace (Preheating furnace model EWL 5636; KaVo, Wangener, Germany.)

\section{Temperature Cycle For Preheating Furnace}

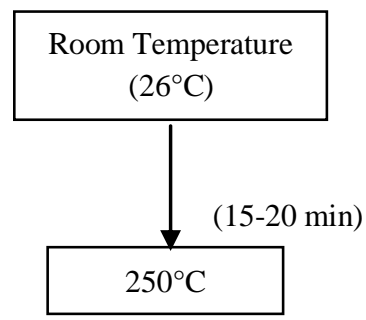

Once the preheating furnace reached the temperature of $250^{\circ} \mathrm{C}$, the molds were transferred from preheating furnace to main heating furnace which had the same temperature as that of preheating furnace i.e. approx. $250^{\circ} \mathrm{C}$

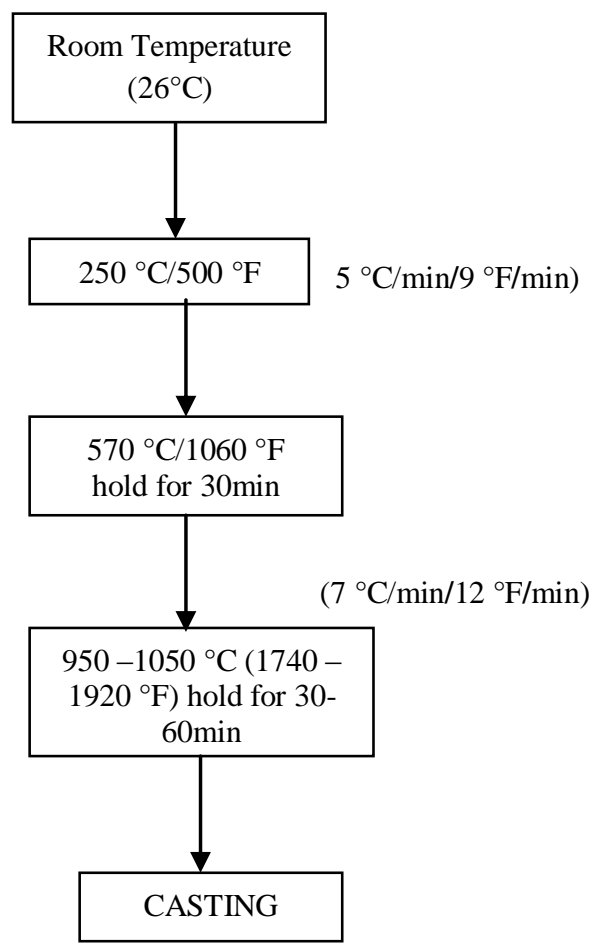

The total time taken for the standard protocol was $3-3 \frac{1}{2} 2$ hours.

\section{Casting}

All the casting were done in an induction casting machine (DUCATRON series- 3, FRANCE) wound 2 $1 / 2$ turns. All the castings were done with $\mathrm{Ni}-\mathrm{Cr}$ base metal alloy (Wiralloy) which was molten at the manufacturer's recommendations by preheating the alloy in ceramic crucible at $950^{\circ} \mathrm{C}$ and then, at casting temperature of $1490^{\circ} \mathrm{C}$ trigger casting when the last solid component has submerged completely in the melt, continue to heat for 0 to 12 seconds depending on the induction capacity of the casting unit. After casting, moulds were allowed to cool down until warm to the touch.

\section{Divesting}

The castings were divested by manually breaking away the investment material as far as possible. Investment materials contain quartz which causes danger of lung harms (silicosis, lung cancer) if inhaled. To avoid dust during deflasking, the moulds are placed in water after they have cooled down completely after casting until they are thoroughly moistened. Investment material that was tenacious and difficult to remove manually (especially between sprues were removed by using 110/150 microns alumina particles in a sandblasting unit (MINI SAB 2 TISSI, Milano- ITALY) at 0.4 MPa pressure. To remove residual investment, 
steam jet was used and then ultrasonically cleaned in distilled water for 15 minutes, rinsed, and dried (Soniclean).

After washing, sprues were cut with an ultra-thin abrasive disc, the post surfaces of the castings were then inspected for nodules. Castings having more than 1 internal nodule or with nodules at either site of measurement were rejected. Single nodule of $0.25 \mu \mathrm{m}$ diameter or less were removed with a round bur, castings with any nodules greater than $0.25 \mu \mathrm{m}$ diameter were rejected. All castings were steam jet cleaned.

\section{Cementation Of Posts}

Custom posts are cemented to 20 teeth (Group A) using dual cure adhesive resin cement (3M, U-100) [FIG 22]. The dual cure resin cement is available in the 3M ESPE Clicker Dispenser containing base and catalyst paste. The base and catalyst ratio is standardized by dispensing the cement of each click. Each clicker dispenser contains $11 \mathrm{gms}$ of RelyX U100 cement which can be dispensed in approximately 80 individual doses. The pastes are mixed on a mixing pad using stainless steel spatula according to manufacturer instruction.

Similarly posts were cemented to 20 teeth (Group B) using type I Glass ionomer cement (Fuji I) [FIG 23] with a powder/ liquid ratio of $1.8 \mathrm{gm} / 1 \mathrm{cc}$. Standardization of the mixes were assured by proportioning the cement powder on a precision scale and the liquid dispensed with a $1 \mathrm{cc}$ insulin syringe. The cement was mixed according to the manufacturer's instruction using a clean plastic agate spatula on a mixing pad.

Remaining posts were cemented to 20 teeth (Group C) using zinc phosphate cement [FIG 24]. The powder liquid ratio is taken according to the manufacturer instruction. The cement is mixed on a clean cool glass slab using stainless steel cement spatula to a thick luting consistency ${ }^{3}$.

During the cementation of the posts, initially the canal was coated with the Cement using a number 30 lentulospiral and the remaining mix was coated onto the post ${ }^{3,8}$. This was done to minimize incorporation of air voids within the cement layer as the post was placed into the post space and to facilitate the coating of the entire length of the post with the cement ${ }^{9}$. After the post was placed inside the canal, complete seating of the post was ensured by applying finger pressure ${ }^{3,9,11}$. After complete seating of the post, excess cement was removed, and the tooth surface was dried to eliminate any visible debris ${ }^{15}$. Specimens luted with dual cure resin cement were light cured for complete setting [FIG 21].

\section{Mounting Of The Samples}

Following the cementation of posts to the teeth, the teeth were stored in physiological saline solution at room temperature for seven days before testing ${ }^{15}$. After 1 week the teeth were prepared for mounting ${ }^{14}$. Notches were prepared in the roots to prevent dislodgement from the embedding material during testing ${ }^{1,4,7}$.

Each tooth was then mounted onto plastic cylindrical tubes using autopolymerising acrylic resin ${ }^{1,7,15}$ (DPI, Cold Cure) [FIG 10] with the help of a surveyor (NEY) [FIG 12].

\section{Testing Of The Samples}

Each acrylic resin block were attached to the jig [FIG 13] and was mounted firmly to the lower jaw of a universal testing machine (Lloyd EZ50; Lloyd instrument) ${ }^{1}$ [FIG 26]. The posts were then tested for the retention, the ability to withstand tensile force exerted by the universal testing equipment [FIG 25]. The testing machine was adjusted for a crosshead speed of $1 \mathrm{~mm} / \mathrm{min}$ and a tensile range of 0 to $50 \mathrm{~kg}$. The load was gradually increased until the post was displaced from the root canal. Determination of displacement was recorded as a sudden release of load as the post as seen on the recording graph. During testing, specimens with any breakage of the tooth or post or the acrylic block were discarded and the new specimens were used.

\section{Results}

Sixty freshly extracted single rooted mandibular premolars free from caries, restoration or cracks were use as specimens to evaluate the tensile strength of three different luting cements using custom made posts. A comparative study consisting of 60 specimens, divided into 3 groups, each containing 20 teeth.

Group A - posts luted with dual cure adhesive resin cement

Group B - posts luted with glass ionomer luting cement.

Group C - posts luted with zinc phosphate cement.

All the specimens were subjected to tensile bond strength using an Instron universal testing machine, adjusted for a cross head speed of $1 \mathrm{~mm} / \mathrm{min}$ and a tensile range of 0 to $50 \mathrm{kgs}$. The load at which the fracture occurred was recorded in kilograms (kgs) as shown in TABLE-1. Mean tensile bond strength of three groups and the P - Value is given in TABLE-2 and GRAPH-1. The mean tensile bond strength for Group A was the highest. It produced bond strength of 20.425 with a low value of $16.8 \mathrm{kgs}$ and a high value of 25.4

In Group B specimens the mean tensile bond strength was 10.055, which was in between the other two groups. Group C specimens produced the mean tensile bond strength of 8.76, which was the lowest value among the 3 groups. The data obtained from the study was analyzed for difference among the luting efficiency of the 
cements using Analysis of Variance (ANOVA) technique. TABLE 3 represents the ANOVA chart which shows that there is a significant difference between the three groups with respect to the tensile strength $(\mathrm{P}<0.001)$.

In order to find out among which pair of groups there exists a significant difference, we carry out the multiple comparison (Post - Hoc test) using Bonferroni method and the results were obtained, which is represented in

TABLE 4. From this table we see that there is a significant difference between Group A and Group B $(\mathrm{P}<0.001)$. We also notice a significant difference between Group A and Group $\mathrm{C}(\mathrm{P}<0.001)$. But we see that there is no significant difference between Group B and Group $C(P>0.05)$. The mean plot of the tensile strength of all the three groups is represented in GRAPH-3. Based on the results in TABLE 4 we conclude that Group A yields a higher tensile strength compared to Group B and Group C and the difference in the tensile strength between Group A \& Group B and Group A \& Group C is statistically significant. The tensile strength in Group $\mathrm{B}$ is higher than Group $\mathrm{C}$ but the difference is not statistically significant.

TABLE - 1: Results Obtained

\begin{tabular}{|c|c|c|}
\hline GROUP - A & GROUP - B & GROUP - C \\
\hline 22.6 & 11.6 & 8.75 \\
\hline 23.9 & 9.9 & 7.75 \\
\hline 16.8 & 10.3 & 8.05 \\
\hline 17 & 11.5 & 8.85 \\
\hline 21.2 & 11.8 & 10.35 \\
\hline 17.3 & 9.7 & 7.85 \\
\hline 19.1 & 8.4 & 9.35 \\
\hline 17 & 11.6 & 9.45 \\
\hline 23.5 & 8.2 & 7.75 \\
\hline 18.4 & 9.2 & 8.05 \\
\hline 25.4 & 11.6 & 9.05 \\
\hline 18.5 & 10.2 & 8.85 \\
\hline 17 & 10.9 & 9.15 \\
\hline 21.9 & 8.9 & 8.15 \\
\hline 21.5 & 8.4 & 9.75 \\
\hline 20.7 & 9.8 & 8.45 \\
\hline 21.3 & 9.1 & 8.35 \\
\hline 22.7 & 9.5 & 9.65 \\
\hline 21.7 & 10 & 8.95 \\
\hline 21 & 10.5 & 8.65 \\
\hline
\end{tabular}

TABLE - 2: The Various Computations And The P-Value

\begin{tabular}{|l|c|c|c|c|c|}
\hline $\begin{array}{l}\text { Tensile Strength } \\
\text { (Kg/cm) }\end{array}$ & N & Mean & $\begin{array}{r}\text { Std } \\
\text {.Deviation }\end{array}$ & Minimum & Maximum \\
\hline Group A & 20 & 20.425 & 2.6215 & 16.8 & 25.4 \\
\hline Group B & 20 & 10.055 & 1.1632 & 8.2 & 11.8 \\
\hline Group C & 20 & 8.76 & 0.7232 & 7.8 & 10.4 \\
\hline
\end{tabular}

TABLE - 3: Anova

\begin{tabular}{|l|l|l|l|l|l|}
\hline & Sum of squares & Df & Mean Square & F & Sig \\
\hline Between groups & 1635.241 & 2 & 817.621 & 280.369 & .000 \\
\hline Within groups & 166.225 & 57 & 2.916 & & \\
\hline Total & 1801.466 & 59 & & & \\
\hline
\end{tabular}

TABLE - 4: Multiple Comparisons

Dependent variable: Tensile Strength $(\mathrm{Kg} / \mathrm{cm})$ Bonferroni

\begin{tabular}{|c|l|l|l|c|c|}
\hline (I)Group (J) Group & $\begin{array}{l}\text { Mean } \\
\text { Difference } \\
\end{array}$ & Std.Error & Sig. & \multicolumn{2}{|c|}{$95 \%$ confidence interval } \\
\cline { 4 - 6 } & & & $\begin{array}{l}\text { Lower } \\
\text { Bound }\end{array}$ & $\begin{array}{c}\text { Upper } \\
\text { Bound }\end{array}$ \\
\hline Group A Group B & $10.3700^{*}$ & .5400 & .000 & 9.038 & 11.702 \\
Group C & $11.6650^{*}$ & .5400 & .000 & 10.333 & 12.997 \\
& & & & & \\
\hline Group B Group A & $-10.3700^{*}$ & .5400 & .000 & -11.702 & -9.038 \\
Group C & 1.2950 & .5400 & .059 & -.037 & 2.627 \\
\hline Group C Group A & $-11.6650^{*}$ & .5400 & .000 & -12.997 & -10.333 \\
Group B & -1.2950 & .5400 & .059 & -2.627 & .037 \\
\hline
\end{tabular}


*The mean difference is significant at the .05 level

GRAPH - 1: Mean Tensile Strength In The Groups

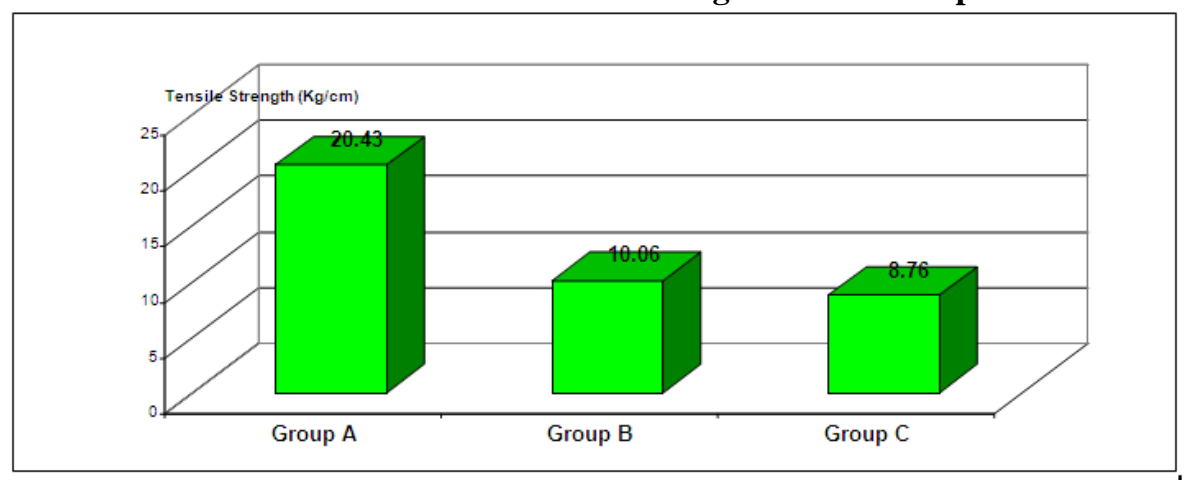

\section{Statistical Analysis}

The results obtained from Instron universal testing machine were recorded in kilograms. Mean and Standard Deviations were calculated. The Means of 3 groups were compared using Analysis of Variance (ANOVA) ${ }^{1}$. Later multiple comparisons (Post - Hoc test) using Bonferroni method to find out among which pair of groups there exists a significant difference.

\section{Summary And Conclusion}

Most teeth that require endodontic therapy have already endured the ravages of advanced dental disease. The endodontic procedure itself further endangers the remaining tooth structure predisposing the tooth failure as a result of crown or root fracture. Therefore posts are often used in endodontically treated teeth to aid in the retention of the core, which helps to replace lost coronal tooth structure and retains the final restoration without compromising the apical seal of the endodontic filling. However, it cannot succeed without the aid of a luting cement to enhance retention and create a seal along the canal walls. Therefore, a durable post is dependent to some extent on the luting agent used to retain it.

Various cements are introduced in the market everyday. Many claim superiority in rate of setting, working and handling characteristics, strength etc. of these the claims of superior retentive strength has more significance in its contribution to success of post and core system or fixed prosthesis.

The following conclusions were drawn from the study:

1. Rely X U-100(3M ESPE) dual cure adhesive resin cement has got a superior retentive strength than any other luting cement.

2. Glass ionomer cement (FUJI-1GC) was found to have slightly higher retentive property than Zinc phosphate cement (Harward), but there was no much statistical significance in the difference between these two cements. 